\title{
Simulation and Optimization Study on Layout Planning of Plant Factory Based on WITNESS
}

\author{
Li Ma ${ }^{1}$, Meiqiong $\mathrm{Ma}^{1}$, Chao $\mathrm{Ma}^{2}$, Jingwen Deng ${ }^{1}$, Xingluo Liu ${ }^{1}$ Lijun Zhao ${ }^{1}$ \\ ${ }^{1}$ Engineering College, Northeast Agricultural University, Harbin 150030, China \\ ${ }^{2}$ Shandong Kerui Petroleum Equipment Co.,Ltd, Dongying 257100, China \\ ${ }^{1}$ Drizzlem19@163.com,976385597@qq.com
}

\begin{abstract}
The emergence of plant factory has solved great restriction problem of natural environment in the traditional agriculture. Therefore, it has been the research concentrate on the facility agriculture in recent years. However, the reasonability of factory's production process and layout determines quality of the product, production efficiency and economic benefits. This paper took Wuchang Jingtian Plant Factory as an example, analyzed the production process and layout and provided a corresponding improvement scheme which was verified by the WITNESS simulation software. An optimal solution was determined from the evaluation index of production efficiency, busy rate, production cycle etc.. Besides, the simulation analysis of production cost before and after the improvement verified the improved plant factory operation is effective and feasible. This improvement scheme not only improved efficiency of production system of the plant factory, but also reduced the operating cost.
\end{abstract}

Keywords: Plant Factory, Process Improvement, WITNESS Simulation, Production Efficiency, Operating Cost.

\section{Introduction}

Plant factory is a efficient agricultural system aiming to realize the continuous production by a kind of high precision environment control in the facility. It is an automatic control of environmental conditions in the process of plant growth by computer ${ }^{[1]}$. The plant factory makes full use of modern industry, biological technology, nutrient solution cultivation and information technology and other means technology, and the development direction is mainly in large-scale plant factories and micro plant factory (family plant factory). But the high cost, the few studies on crop type and the low intelligence level have become the main reasons hindering plant factory put into practical application ${ }^{[2]}$. In recent years, plant factory has become the center of facility agriculture research. However, most of the researches are about the key technology, internal environment, control system etc., which ignore the study of production process and layout planning within the plant factory. Many European countries are committed to the plant factory research and development from the direction of saving resources and reducing the production cost through the use of a computer system to implement intelligent monitoring, which makes operating costs of the whole production system fallen sharply, making plant factory to further promote and expand ${ }^{[3]}$. However, a good production process and the reasonable production workshop layout inside plant factory affect the product quality, productivity, efficiency and economic benefit of enterprises.

For workshop layout problems of the most small plant factory in our country, the paper took production workshop of Wuchang Jingtian Plant Factory of Heilongjiang Province as an example to carry out field investigation through surveying data to analyze the present production situation and finding out the existing problems. Combining with theoretical 
knowledge, this paper used process analysis method to improve the production process, optimized the defects of production layout and established the production cost analysis model. Meanwhile, WITNESS software was used to simulate the production process, layout and cost before and after improvement and the simulation data were compared and analyzed.

\section{Analysis of Plant Factory Production Status}

Wuchang Jingtian Plant Factory is completely sealed structure, whose inside has four greenhouses, and each greenhouse has 50 tables with dimensions of $1.5 * 9 \mathrm{~m}$. There is a $30 \mathrm{~cm}$ wide aisle in the middle of five tables. The plant factory uses soil cultivation and has the length and width of $30 \mathrm{~cm}$ 's sown board with 38 holes which could plant 38 plants. Cultivation of the crop is in spring and autumn. In this paper, we take research for the crop in spring. The period of spring crop is from January 1st to June 1st, and there are three main crops: tomato, cucumber and eggplant. The corresponding planting number is cucumber 110000 trains, 160000 trains, 275000 trains respectively.

The entire production process of plant factory is shown in Figure1: First of all, the seeds will be transported from the warehouse to the nursery room to do manual sowing. Then the greening seedlings cultivated in nursery room will be transplanted to green room by a vehicle. Finally, green products will be packed in the box and transported out of the factory for sale or further grow.

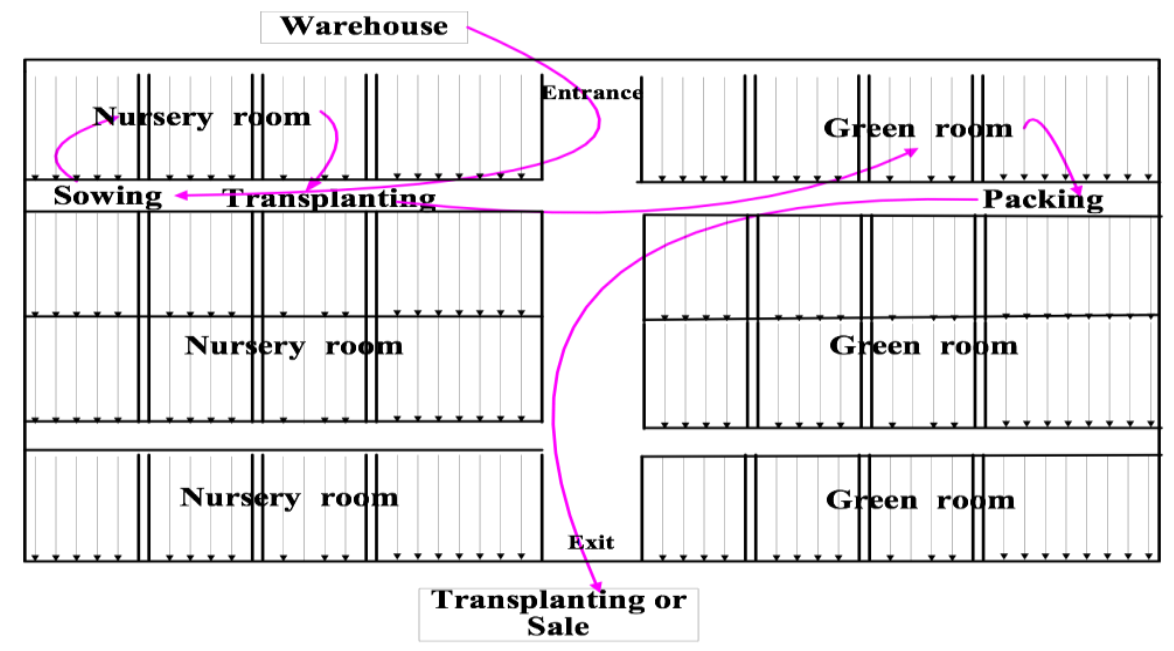

Figure 1. The Production Process and Personnel Movement Circuit Diagram

Through investigation and analysis, we found that there are some problems in the existing production method of the plant factory:

(1) Manual sowing rate is slow. Sowing is completed within the specified time (three days) requires too much manpower and it is more difficult to hire workers in the busy sowing period.

(2) The process of transplanting seedlings is very difficult and the mortality rate is too high. According to the survey results we knew that seedling mortality rate could reach $10 \%-15 \%$ and transplanting seedlings requires lots of workers accounting for $49.8 \%$ in total.

(3) Because shifting seedlings from the seedling tray is difficult and slow, three transport workers must wait for $10 \mathrm{~h}$ to carry a batch of seedlings to green room. The process of removing plant factory after harvest also has the above problems, such as transport personnel for five people, waiting for $0.5 \mathrm{~h}$, which lead to the waste of human resources and time. 
(4) There is a large amount of logistics in the station layout, and long transport distances between some stations.

\section{Improvement Scheme}

According to the current production situation and existing problems of plant factory of Wuchang Jingtain Agriculture Co.,Ltd., we applied the system layout planning (SLP) method to optimize and improve the original layout, which seed warehouse, packaging or transplanting operation unit position has been adjusted (see Figure 2) and the improved transport distance decreased significantly. At the same time, the improvement scheme was put forward to the existing production way:

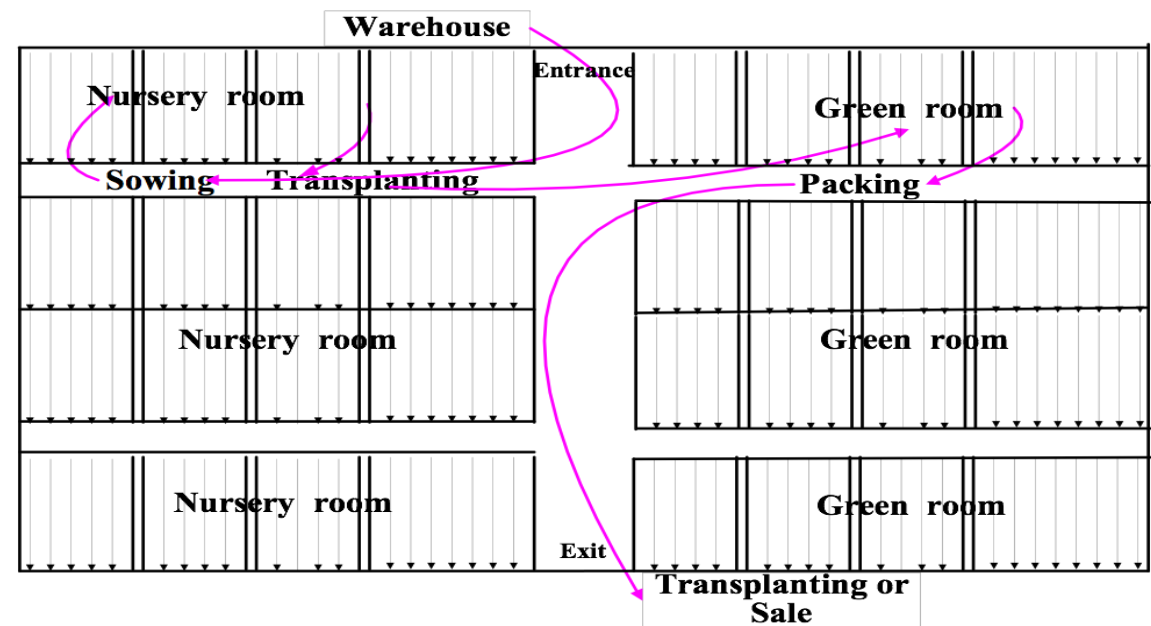

Figure 2. The Production Process and Layout after the Improvement

(1) Change the traditional manual planting and select the suitable sowing machine for the plant factory's seedling tray. Combining the plant factory existing seedling plate hole number, seed features, price with other constraints through market research, we choose pressure points flip-precision seeder (model is $2 \mathrm{BXP}-500$ ). The constraint conditions of equipping quantity for planter are as follows:

$a * v * t * x \geq F$

$x \geq 0$

Where, $a$ is the number of holes for seeding plate (38holes), $v$ is seeder sowing speed (315 trays/h), $t$ is the needed time for the slowest completion of sowing ( 3 days), $x$ is the number of planter, $F$ is the number of planted seedlings. According to the present planting situation, the number of the seeding machine can be obtained for 2 units.

(2)Manual vehicle transport to a flat belt conveying. Through market research, the turning conveyor belt (model for norbans-p05) was selected to finish the delivery process from the nursery to the green room and ship out the factory so as to speed up the delivery rate, remove temporary storage procedure and reduce the loss rate of seedlings. The type of conveyor has simple structure, easy to maintain, low power consumption, low investment costs. After the actual measurement we give desired length of the conveyor $196 \mathrm{~m}$ for the plant factory.

Through the improvement of the above aspects, before and after comparison of process improvement is shown in table1:

Table 1. A Comparison Before and After the Improvement

\begin{tabular}{cccc}
\hline Name & Distance/m & Time/h & Worker \\
\hline
\end{tabular}




\begin{tabular}{ccccccc}
\hline & Initial & Improved & Initial & Improved & Initial & Improved \\
\hline Seed to nursery room & 705 & 655 & 9 & 0.1 & 1 & 1 \\
Sowing & & & 41 & 36 & 35 & 1 \\
Transplanting to green room & \multirow{2}{*}{1343} & 967 & 14 & 3 & 105 & 2 \\
Picking & & & 14 & 14 & 15 & 15 \\
Out of green room & \multirow{2}{*}{1125} & 625 & 1.5 & 1.5 & 15 & 15 \\
Waiting & & & 2.5 & 0 & 20 & 0 \\
Packing or Transplantation & & & 9 & 9 & 20 & 1 \\
\hline
\end{tabular}

As can be seen from table 1, the workers number of operation procedure has been reduced by 34 ; the transport procedure time decreased by $11.2 \mathrm{~h}$, the distance decreased by $376 \mathrm{~m}$, the number of people decreased by 103 ; the waiting procedure was canceled, and the number of people was reduced by 20 .

\section{Modeling Simulation}

In order to verify the rationality and feasibility of the improved scheme and show a clear implementation process and effect analysis on production process and layout before and after improvement, the WITNESS software was used to simulate the production process and layout before and after the improvement, the model flow is shown in Figure 3.

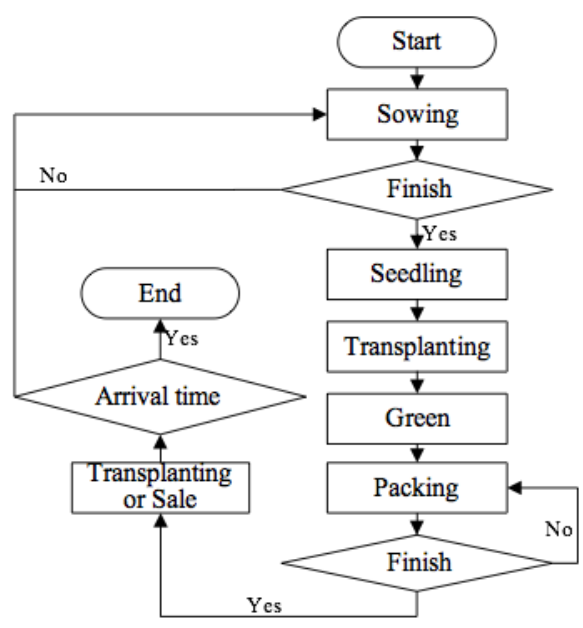

Figure 3. Model Operation Flow

In this case, with a WITNESS computer simulation to describe the actual production system are simplified approximation model as shown in Figure 4. The plant factory process as a variable line, cucumber, eggplant, tomato, three kinds of crops in accordance with the time interval of $6 \mathrm{~h}, 8 \mathrm{~h}, 2.4 \mathrm{~h}$ and a batch of 5500 strains take turns to produce in planning period. Only one product can be produced during each interval, and after the completion of the specified volume, the other product can be transferred. In the model, a table to grow as a batch number, there are 150 seedling trays on each table, which can be planted 5700 strains crop, the output rate is $97 \%$, then the number of a batch is 5500 strains. 


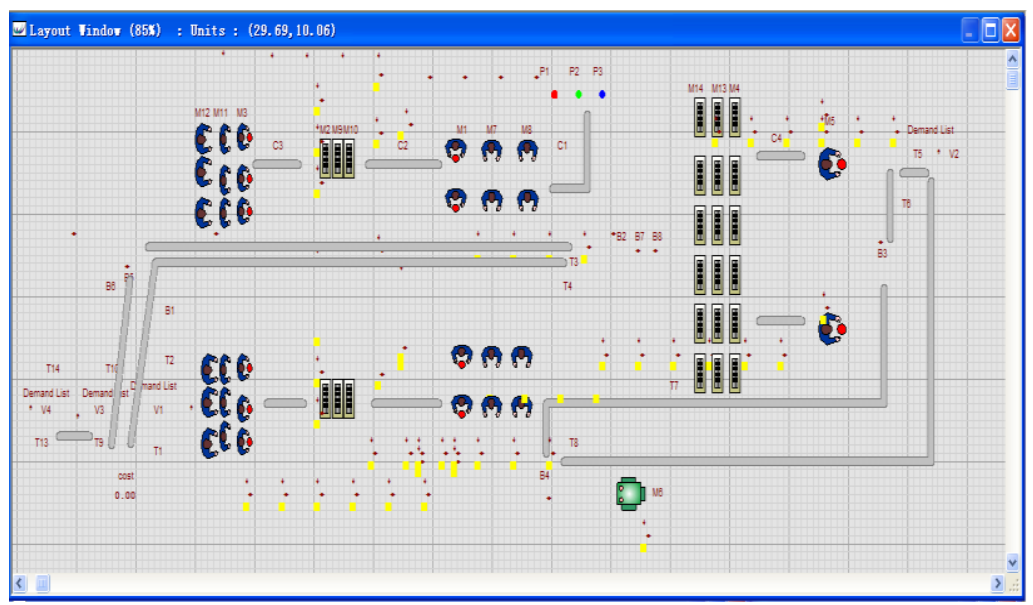

Figure 4. The Production Simulation Model of Plant Factory

Table 2. Statistical Table for each Working Procedure

\begin{tabular}{cccccccc}
\hline Element & Number & Explanation & Time/h & Element & Number & Explanation & Time/h \\
\hline M1 & 4 & $\begin{array}{c}\text { Cucumber } \\
\text { sowing }\end{array}$ & 11.5 & M8 & 4 & Tomato sowing & 9.2 \\
M2 & 2 & $\begin{array}{c}\text { Cucumber } \\
\text { sowing }\end{array}$ & 10.08 & M9 & 2 & $\begin{array}{c}\text { Eggplant } \\
\text { seedling }\end{array}$ & 15.62 \\
M3 & 6 & $\begin{array}{c}\text { Cucumber } \\
\text { transplant } \\
\text { Cucumber }\end{array}$ & 17.7 & M10 & 2 & Tomato seedling & 8.064 \\
M4 & 6 & $\begin{array}{c}\text { green } \\
\text { Packing }\end{array}$ & 0.074 & M12 & 6 & $\begin{array}{c}\text { Eggplant } \\
\text { Transplant } \\
\text { Tomato }\end{array}$ & 27.43 \\
M5 & 2 & $\begin{array}{c}\text { Transplant } \\
\text { Packing or } \\
\text { transplant }\end{array}$ & 0.564 & M13 & 6 & Eggplant green & 46.83 \\
M6 & 1 & $\begin{array}{c}\text { Eggplant } \\
\text { sowing }\end{array}$ & 17.88 & M14 & 6 & Tomato green & 24.17 \\
\hline
\end{tabular}

\section{Analysis of Simulation Results}

The spring crop working time of the plant during ten years is $36000 \mathrm{~h}$, so the running time of the model is set for $36000 \mathrm{~h}$, and the simulation data are shown in table 3-8.

Table 3. The Simulation Data Output of Crop Elements

\begin{tabular}{ccccc}
\hline \multicolumn{2}{c}{ Name } & P1(Cucumber) & P2(Eggplant ) & P3(Tomato ) \\
\hline \multirow{2}{*}{ No. Enter } & Initial & 1078 & 693 & 1347 \\
& Improved & 1078 & 693 & 1347 \\
\multirow{2}{*}{ No. Ship } & Initial & 1057 & 679 & 1321 \\
& Improved & 1066 & 686 & 1330 \\
\multirow{2}{*}{ W.I.P } & Initial & 21 & 14 & 26 \\
& Improved & 12 & 7 & 17 \\
Ave W.I.P & Initial & 23.06 & 14.83 & 28.83 \\
& Improved & 14.35 & 9.44 & 17.19 \\
Ave Time & Initial & 89.34 & 139.08 & 71.45 \\
& Improved & 83.69 & 130.15 & 66.95 \\
\hline
\end{tabular}

As can be seen from table 3, after improving, cucumber, eggplant, tomatoes, three products output volume is increased, the amount of W.I.P is reduced, the production cycle is shortened significantly, and the system output is improved obviously. 
Table 4.The Simulation Data Output Table of Machine Elements

\begin{tabular}{ccccccc}
\hline \multirow{2}{*}{ Name } & \multicolumn{2}{c}{ \%Idle } & \multicolumn{2}{c}{ \%Busy } & \multicolumn{2}{c}{ No. of Operation } \\
\cline { 2 - 6 } & Initial & Improved & Initial & Improved & Initial & Improved \\
\hline M1 ( P1 sowing) & 14.26 & 17.03 & 85.74 & 82.97 & 269 & 1077 \\
M7 (P2 sowing) & 6.32 & 10.55 & 93.68 & 89.45 & 173 & 693 \\
M8 (P3 sowing) & 31.40 & 16.32 & 68.60 & 83.68 & 336 & 1342 \\
$\begin{array}{c}\text { M3 (P1 seedling } \\
\text { transplantation) }\end{array}$ & 9.26 & 48.62 & 90.74 & 51.38 & 178 & 535 \\
$\begin{array}{c}\text { M11 (P2seedling } \\
\text { transplantation) }\end{array}$ & 4.57 & 30.97 & 95.43 & 69.03 & 115 & 345 \\
$\begin{array}{c}\text { M12 (P3seedling } \\
\text { transplantation) }\end{array}$ & 27.41 & 58.90 & 72.59 & 41.10 & 223 & 669 \\
\hline
\end{tabular}

As can be seen from table 4, after improving, the busy rate of M1, M7, M8 are relatively balanced, output is increased significantly, which indicates planter replacing manual seeding makes seeding efficiency improved significantly; Meanwhile, the busy rate of M3, M11, M12 declined, workers have proper rest, transplanting seedlings efficiency has been increased .

Table 5.The Simulation Data Output Table of Conveyor Elements

\begin{tabular}{ccccccccc}
\hline \multirow{2}{*}{ Name } & \multicolumn{2}{c}{ \%Empty } & \multicolumn{2}{c}{ \%Move } & \multicolumn{3}{c}{ Now On } & \multicolumn{2}{c}{ Total On } \\
\cline { 2 - 8 } & Initial & Improved & Initial & Improved & Initial & Improved & Initial & Improved \\
\hline $\begin{array}{c}\text { C1 (P1 to } \\
\text { nursery room) } \\
\text { C7 (P2 to }\end{array}$ & 38.74 & 42.64 & 61.26 & 57.36 & 1 & 1 & 1078 & 1078 \\
$\begin{array}{c}\text { nursery room) } \\
\text { C8 (P3 to } \\
\text { nursery room) }\end{array}$ & 20.73 & 26.35 & 79.27 & 73.65 & 0 & 0 & 693 & 693 \\
\hline
\end{tabular}

As can be seen from table5, the lower work time and busy rates of C1, C7, C8 suggests that the layout optimization of logistics transport efficiency was improved due to reduced transportation distance.

Table 6.The Simulation Data Output Table of Vehicle Elements

\begin{tabular}{ccc}
\hline Name & \% Idle & \% Loaded \\
\hline V1 (Vehicle carrying P1) & 26.38 & 73.62 \\
V2 (Vehicle carrying P2) & 2.37 & 97.63 \\
V3 (Vehicle carrying P3) & 14.57 & 85.43 \\
V4 (Vehicle out of factory) & 41.11 & 58.89 \\
\hline
\end{tabular}

Table 7.Track Elements Simulation Data Output Table

\begin{tabular}{ccccc}
\hline Name & \% Empty & \% Busy & \% Block & No. O \\
\hline T1 (V1 Parking ) & 5.31 & 1.73 & 92.96 & 1065 \\
T9 (V3 Parking ) & 2.89 & 2.35 & 94.76 & 686 \\
T13 (V4Parking) & 8.99 & 1.38 & 89.63 & 1330 \\
T5 (V2Parking ) & 1.24 & 0.14 & 98.62 & 3066 \\
\hline
\end{tabular}

Table.8 Improved Conveyor Elements Simulation Data Output

\begin{tabular}{ccccc}
\hline Name & \%Empty & \%Move & Now On & Total On \\
\hline C4 (P1 seedling to greenhouse) & 47.21 & 52.79 & 1 & 1069 \\
C13 (P2 seedling to greenhouse) & 37.91 & 72.09 & 1 & 688 \\
C14 (P3 seedling to greenhouse) & 57.77 & 42.23 & 1 & 1337 \\
C6 (Out of factory) & 36.24 & 63.76 & 1 & 3069 \\
\hline
\end{tabular}


From table6, 7 and 8 we can see V1, V2, V3, V4 with serious blocking before improvement are replaced by $\mathrm{C} 4, \mathrm{C} 6, \mathrm{C} 13, \mathrm{C} 14$, respectively. It indicates that the delivery procedure from the nursery room to green room and out of plant factory replaced by a conveyor transport, transport efficiency improved significantly.

\section{Production Cost Analysis}

In this paper, in addition to production process we also take modeling and simulation on production cost before and after improvement. Define a new variable element: Cost, which is expressed as:

$F=Q+10\left(\sum_{i=1}^{n} a b x_{i}+\frac{y-y_{1}}{10}+\frac{z-z_{1}}{10}\right)$

Where, $F$ is the total cost; $Q$ is fixed costs; $x_{\mathrm{i}}$ is the $i$-th worker; $a$ is the cost of every day for each of the workers; $b$ is the working days per year for each worker; $n$ is the number of workers; $y$ represents the original value of the planter; $y_{1}$ represents the estimated residual value of planter; $z$ is the original value of conveyor belt, $z_{1}$ is the estimated residual value for the belt.

Before improving, the production costs mainly include personnel wages and the input of fixed costs in production process. It increased the depreciation of seed machine, conveyor and conveyor belt after the improvement. According to the survey we know that fixed planting cost of plant factory in the spring is $¥ 600000 /$ year; Worker cost is $Y$ $100 /$ day; Machine price is $¥ 35000 /$ set; The length of conveyor belt is $196 \mathrm{~m}$, the price is $¥ 700 / \mathrm{m}$; Machine and conveyor belt is expected to update time for 10 years. After ten years, the expected residual value of seeder is $¥ 5000 / \mathrm{set}$, the conveyor belt is $¥ 100 / \mathrm{m}$. After running the model $36000 \mathrm{~h}$, simulation results of production cost before and after the improvement as shown in Figure 5.

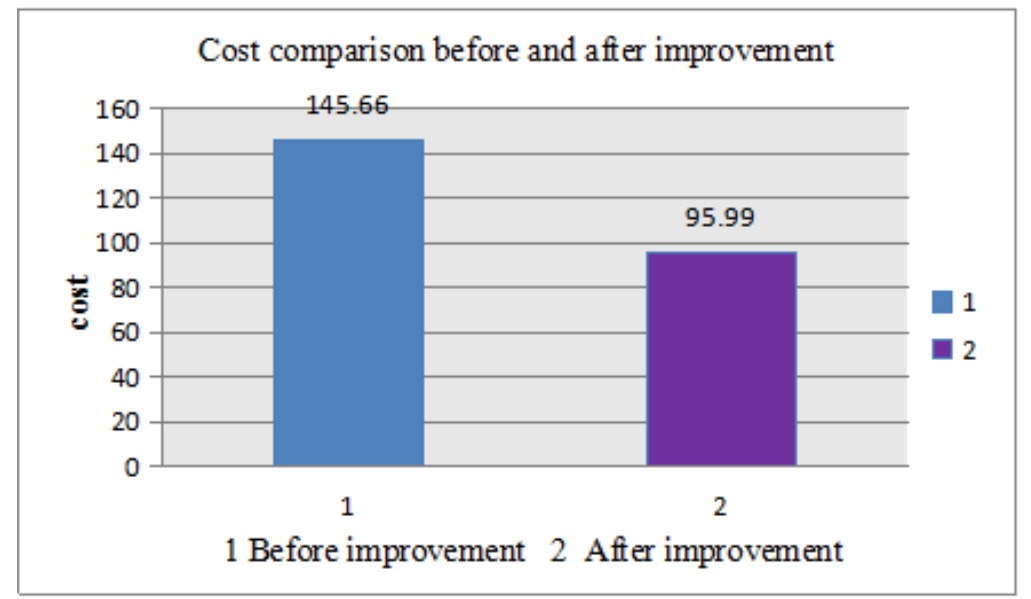

\section{Figure 5. A Comparison of Production Cost before and After the Improvement}

Before the improvement, production cost is $¥ 1.4566$ million, after the improvement, the simulation cost is $¥ 959900$, which was reduced by $34.1 \%$, which has important effect to improve economic benefit for the enterprise.

\section{Conclusions}

Taking Wuchang Jingtian Plant Factory as the research object, we have carried out an optimization and improvement on the production process and layout planning combined with process analysis and the theory of WITNESS modeling and simulation. For the 
improved production system, the total number of workers has been reduced by 137 , handling time and distance respectively reduced by $18.7 \mathrm{~h}$ and $962 \mathrm{~m}$. Besides, the breakage rate of seedlings became lower, the total production rate was accelerated, and production cycle became shorter. Meanwhile, it saved production costs about 34\% for enterprises and made production process automation degree of the plant factory higher. In a word, the research result provided a scientific basis for process and layout planning and design of plant factory.

\section{Acknowledgments}

Doctoral Fund of Northeast agricultural University(2012RCB7).

\section{References}

[1] Q Yang, C Zhang. Plant Factory Series (1)—Plant Factory Definition and Classification. Rural Practical Engineering Technology (Green House Gardening). 5, 36-37(2005).

[2] Z Qiu, L Zhao, H Jia. Analysis on the Development Trends and Problems of Plant Factory. Agricultural Mechanization Research. 10, 230-233(2013).

[3] Z Gu, B Liu. Test Design of Plant Factory. Tianjin Agricultural Sciences. 1, 34-40(1997).

[4] S Liu. Study on Artificial Lighting Used in the Closed Plant Factory. Chinese Academy of Agricultural Sciences (2007).

[5] L Ma, S Wang, Y Wang, Simulation Study of Equipment in Harvest Machinery System by WITNESS. Journal of Northeast Agricultural University. 42(5), 58-63(2011).

[6] K Zhou, B Wang, J Liu, C Yao, R Zhang. Simulation Model of Work-In-Progress Control base on a Motorcycle Engine Assembly Line. Computer Integrated Manufacturing System.16(11), 24502453(2010).

[7] Y Wang, H Ma, Modeling and Simulation of the Production Logistics System. Science Press, Bei Jing(2006).

[8] L Liu, D Wang. Witness-Based Simulation and Optimization of Production Line in a Manufacturing Plant. Industrial Engineering. 15(1), 109-114(2012).

[9] J Mao, J Qiao, L Wang, Y Wang. Simulation Study on Production Flow in Auto Part Manufacturing Based on Witness. Industrial Engineering Journal. 14(3), 24-127(2011).

[10] L Liu, X Wang. Workshop Layout Simulation and Logistics Optimization Based on Digital Factory. Mechanical Engineering \& Automation. 6(3), 25-27(2012).

[11] S Wang, J Wei, R Tang. Modeling and Simulation of Virtual Machining Plant Floor Planning. Modern Manufacturing Engineering.12, 32-33(2006).

[12] L Liu. Research on Modeling and Simulation of Digital Factory in X Company. Industrial Engineering (2012). 